\title{
Mount Device
}

National Cancer Institute

\section{Source}

National Cancer Institute. Mount Device. NCI Thesaurus. Code C50079.

A structural device designed to facilitate the attachment of one object to another. 